\title{
Implantation of Indwelling Pleural Catheter as Treatment of Chronic Effusion Under Ventricular-Assist-Devices Support
}

\author{
Mosab Al Shakaki*, Volkan Kösek and Jürgen Sindermann \\ Department of Cardiothoracic Surgery, University Hospital Muenster, Muenster, Germany
}

\begin{abstract}
Pleural-effusion is a general symptom in cardiac insufficiency even after VAD implantation. Draining of pleuraleffusions improves symptoms without complications. In VAD-patients repeated thoracentesis is associated with higher risk of bleeding, the operative management showed very safe results with more privileges towards video assisted-thoracic-surgery. Nonetheless, operative treatment isn't always feasible. In such cases another approach is required. We found that implantation of indwelling-pleural-catheter is an effective treatment for non-operablepatients as in our Case a spontaneous remission of the pleural-effusion was achieved after 6 months. However, a case of chronic pleural-effusion with indwelling-pleural-catheter and left ventricular-assist-device support has not been previously reported.
\end{abstract}

Keywords: Pleural effusion; LVAD; Left ventricular assist device; Outcome

\section{Introduction}

Even under VAD-therapy, pleural effusion remains a general symptom for patients with congestive heart failure. To improve dyspnea and other symptoms safely, it is necessary to drain the effusion [1]. The operative management of thoracic-effusions in VAD-patients showed safe results with more privileges towards VATS [2] and it could be the treatment of choice, as repeated thoracentesis is associated with higher risk of bleeding due to the anticoagulation. Nonetheless, the operative procedure could be associated with high risk because of some patient-related causes (age, gender, obesity, comorbidities, history of infection, primary diagnosis, and socioeconomic profile). Or sometimes contraindicated if double lumen intubation isn't tolerable [3], so patients with pathological pulmonary-function-tests require another approach for the treatment of pleural-effusions.

Patients with chronic indwelling pleural catheter are relieved from dyspnea, with reduced hospitalizations and maintaining their quality of life safely and effectively [4]. As management of those Patients could take place in the Outpatient clinic. Therefore, compared with inpatientmanagement, it would reduce the length of in-hospital-stay [4].

We found that implantation of indwelling-pleural-catheter is an effective treatment of chronic-effusion in VAD-patients with operativecontraindication or high operative risk. In our case a spontaneous remission of the pleural-effusion, due to adhesions, occurs after 6 months. However, a case of chronic-pleural-effusion with indwellingpleural-catheter and LVAD-support hasn't been previously reported.

\section{Case Report}

We present a 58-year-old patient who suffered from repeated cardiac decompensations due to severe left-sided heart failure following autologous stem-cell transplantation as a therapy of amyloidosis. He underwent the implantation of HeartWare device without postoperative complications. As the patient's pulmonary condition deteriorated slowly, a lung-function-test was performed. Hereby, we found a moderate restriction with mild obstruction and moderate hypoxia. The patient received medical therapy, after a while a long-term oxygen therapy (LTOT) was necessary. During a 9-month-course, several hospitalizations were necessary due to recurrent right sided pleuraleffusions. A chest CT-scan showed no septations (Figures 1a and 1b). Microbiological-studies excluded any infectious etiology. The patient received an indwelling pleural catheter (PleurX-Drainage-system) after

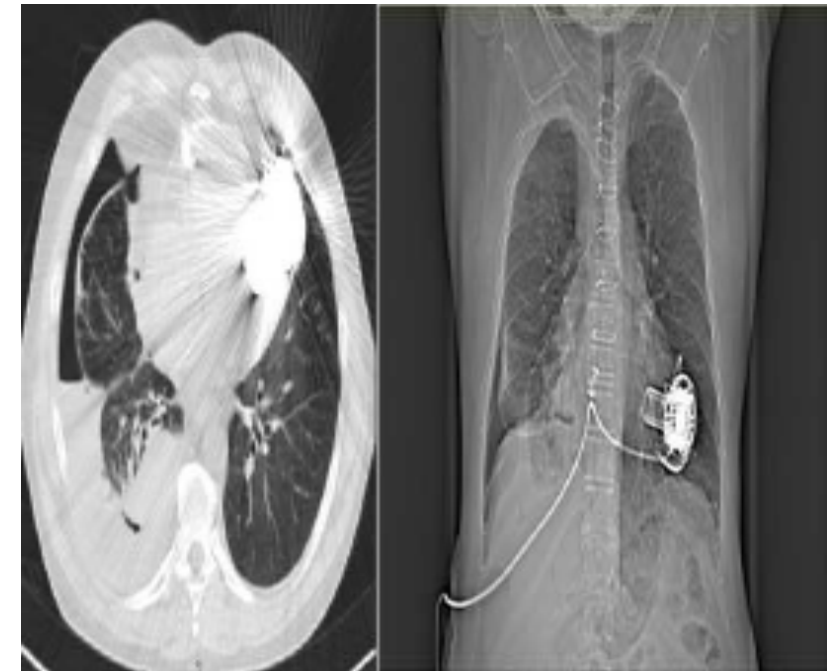

A

B

Figure 1: a. Preoperative, right sided atelectasis and pleural effusion, L-VAD device with x-ray shadow and reflections. b. Preoperative, thoracic overview (CT-Scan) showing the faile-to-expand right lung after draining the accumulated pleural effusion.

multiple Thoracentesis. The indwelling pleural-catheter remained for 6 months. The patient was able to evacuate the pleural-cavity by himself after completing his training course. After 6 months pleural adhesions took place, as a result recurrent effusion were treated. The patient lived 5 years and 7 months with VAD-support and completely treated pleural effusion. He died due to a non-cardiac/pulmonary cause (Figure 2).

*Corresponding author: Mosab Al Shakaki, Department of Cardiothoracic Surgery, University Hospital Muenster, Muenster, Germany, Tel: +49 2518355555 ; E-mail: dr.alshakaki@yahoo.com

Received November 05, 2017; Accepted January 25, 2018; Published January 31,2018

Citation: Al Shakaki M, Kösek V, Sindermann J (2018) Implantation of Indwelling Pleural Catheter as Treatment of Chronic Effusion Under Ventricular-Assist-Devices Support. J Clin Case Rep 8: 1073. doi: 10.4172/2165-7920.10001073

Copyright: ( $) 2018$ Al Shakaki M, et al. This is an open-access article distributed under the terms of the Creative Commons Attribution License, which permits unrestricted use, distribution, and reproduction in any medium, provided the original author and source are credited. 


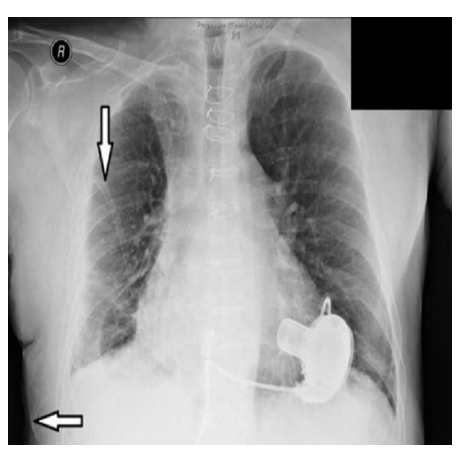

Figure 2: Postoperative, chest X-ray of the patient after implantation of the PleurX Drainage system.

\section{Discussion and Summary}

The benefit of LVAD in patients with left ventricular failure is clear. Such a disease could be associated with comorbidities or complications even under optimal treatment, for example pleural effusion that could require even surgical treatment. The surgery per se is safe [2], but it is not always feasible. The implantation of indwelling pleural-catheter was not discussed in VAD-patients before.

We review a case of treated chronic pulmonary-effusion during VAD-support. The patient required Multiple Thoracentesis because of repeated pleural-effusions. As a diagnostic tool and for the treatmentplan, we performed a CT-Scan. Hereby, a massive right sided pleuraleffusion was detected, the right sided lower lobe showed severe atelectasis with no compliance to inflate. In such situations, a surgical decortication would be very beneficial. However, despite the high risk of bleeding due to anticoagulation, the patient had a deteriorated pulmonary situation with long-term oxygen therapy. As a result, the operative decortication wasn't performed, instead of it the patient underwent into implantation of indwelling-pleural catheter [5].

After completing the short training course, the patient was able to empty his hemi-thorax and release his symptoms by himself. As pleural-adhesions took place, we were able to remove the catheter after 6 months, as result recurrent effusions were treated safely.

\section{Conclusion}

We found that implantation of indwelling-pleural catheter is an effective treatment of chronic effusion in VAD-patients with operativecontraindication or those at high operative risk. However, a case of chronic pleural-effusion with indwelling pleural catheter and VADsupport has not been previously reported.

\section{References}

1. Guha A, Munjampalli S, Bandi V, Loebe M, Noon G, et al. (2008) Pleural effusion after ventricular assist device placement: prevalence and pleural fluid characteristics. Chest 134: 382-386.

2. Sebastien G, Kilic A, Toyoda Y, Bermudez C, Siegenthaler MP, et al. (2012) Minimally invasive approach to thoracic effusions in patients with ventricular assist devices. Interact Cardiovasc Thorac Surg 14: 44-47.

3. Jennifer MH, Berry MF, D'Amico TA (2013) Contraindications of video-assisted thoracoscopic surgical lobectomy and determinants of conversion to open, $\mathrm{J}$ Thorac Dis 3: S182-S189.

4. Joe BP, Walsh GL, Swisher SG, Roth JA, Suell M, et al. (2000) Outpatient management of malignant pleural effusion by a chronic indwelling pleural catheter. Ann Thoracic Surg 69: 375.

5. Lietz K, Long JW, Kfoury AG, Slaughter MS, Silver (2007) Outcomes of left ventricular assist device implantation as destination therapy in the postREMATCH era: implications for patient selection, Circulation 116: 497-505. 